Images in...

\title{
Splenic vein aneurysm
}

\author{
Mehrnaz Asadi Gharabaghi, ${ }^{1}$ Niloofar Ayyoobi Yazdi, ${ }^{2}$ Zahra Abrishami, ${ }^{3}$ Shahab Amini ${ }^{3}$ \\ 1Department of Respiratory Medicine, Imam Khomeini Hospital Complex, Tehran University of Medical Sciences, Tehran, Iran; \\ 2Department of Radiology, Imam Khomeini Hospital Complex, Tehran University of Medical Sciences, Tehran, Iran; \\ ${ }^{3}$ Department of Medicine, Imam Khomeini Hospital Complex, Tehran University of Medical Sciences, Tehran, Iran
}

Correspondence to Dr Mehrnaz Asadi Gharabaghi, asadi m@tums.ac.ir

\section{DESCRIPTION}

A 56-year-old man was referred to our clinic to investigate the chronic diarrhoea and weight loss. He was healthy until 3 months before admission. He gradually developed chronic small bowel-type diarrhoea. He was a retired man with no history of illness in the past. He never smoked. On physical examination, he was ill and wasted. There were pallor and a brown-pigmented, $5 \times 3 \mathrm{~cm}$ skin plaque over the left clavicle. The chest, abdomen, extremities and nervous system were all normal on examination. He had mild anaemia with haemoglobin: $10.8 \mathrm{~g} / \mathrm{dl}$. Tests of body iron stores were normal. Therefore, anaemia was not due to iron deficiency. He underwent upper intestinal endoscopy. Biopsy of duodenum showed normal mucosa and no evidence of absorptive disorders. Total colonoscopy demonstrated three pedunculated polyps in descending colon. Histological study showed low-grade dysplasia in excised polyps. CT scan of abdomen showed thickened jejounal loops and a large splenic vein aneurysm (figure 1).
He then underwent double-balloon enteroscopy. Biopsy showed no sign of infiltrative or malignant disease of bowels. CT angiography of abdominal vessels showed splenic vein and artery aneurysm near the hilum (figure 2A,B). An arterio-venous fistula was possible. Digital subtraction angiography was necessary to exclude the mentioned connection, but he refused to undergo further imaging. The huge splenic vein aneurysm and the backward flow into the superior mesenteric vein impeded the venous drainage of the small bowel. The congested bowel was probable cause of his diarrhoea. Venous system aneurysms including splenic vein are uncommon. Superior mesenteric vein aneurysm is the most common. It usually occurs in patients with portal hypertension. However, its formation does not need portal hypertension. There are a few reports of splenic vein aneurysm, especially in the puerperium. The venous aneurysms are usually asymptomatic. However, there is risk of aneurismal rupture, thrombosis, or local compressive effects. Therefore, surgery remains the treatment

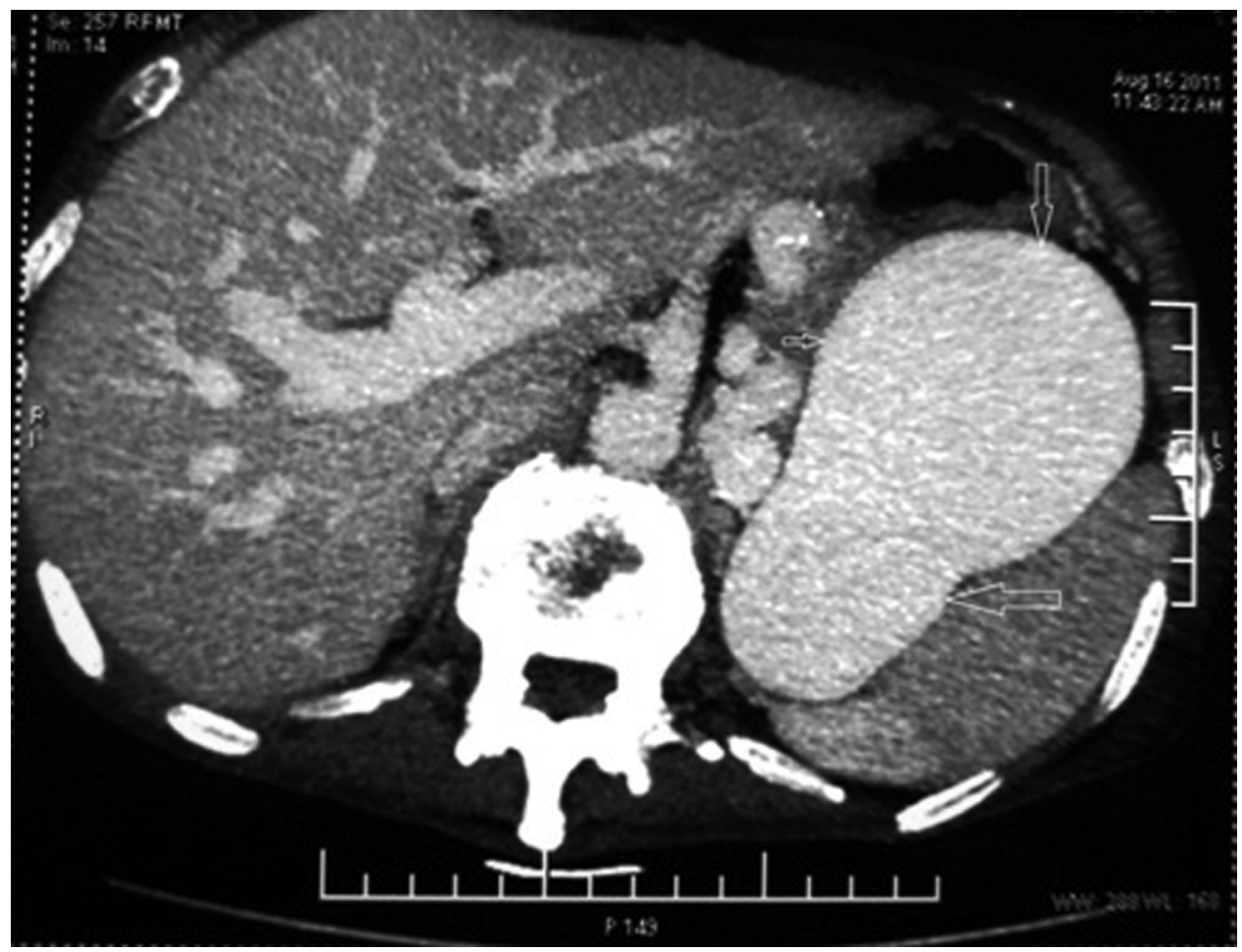

Figure 1 Section of contrast-enhanced abdominal computed tomography scan demonstrating a large $125 \times 65 \mathrm{~mm}$ aneurysm (arrows) in distal portion of splenic vein near the spleen. 


\section{BMJ Case Reports}
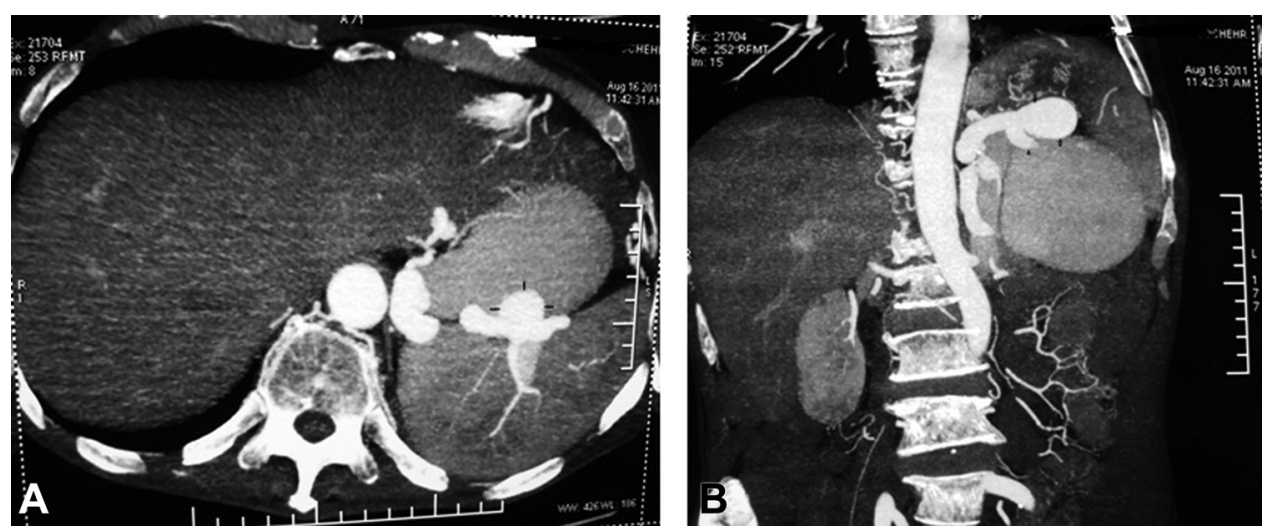

Figure 2 (A, B) Sections of multi-slice spiral contrast-enhanced angiography of abdominal aorta illustrating the same venous aneurysm and a small splenic artery aneurysm (arrows) near the hilum. A suspicious arterio venous connection (arrowhead) is noted between arterial and venous system.

modality of choice for symptomatic patients; otherwise, radiologic survey and follow up are recommended. ${ }^{1-4} \mathrm{We}$ did not perform surgery in the patient because he had no intra-abdominal haemorrhage or abdominal vein thrombosis and biopsy of the skin plaque showed the metastasis of an undifferentiated carcinoma. He was referred to the oncologist.

Competing interests None.

Patient consent Obtained

\section{REFERENCES}

1. Weber G, Milot L, Kamaoui I, et al. [Splanchnic vein aneurysms: a report of 13 cases]. J Radiol 2008;89(3 Pt 1):311-6.

2. Smith TJ, Morehouse DL. Superior mesenteric vein aneurysm rupture. Vasc Endovascular Surg 2011:45:559-60.

3. Parpaglioni R, Metta E, Zagari A, et al. Spontaneous splenic vein aneurysm rupture in the puerperium. Int J Obstet Anesth 2009;18:48-51.

4. Shimoda M, Kubota K, Sakuma A, et al. Intra-abdominal hemorrhage due to rupture of a splenic vein aneurysm: a case report. J Gastrointest Surg 2003;7:683-6.

This pdf has been created automatically from the final edited text and images.

Copyright 2012 BMJ Publishing Group. All rights reserved. For permission to reuse any of this content visit http://group.bmj.com/group/rights-licensing/permissions.

BMJ Case Report Fellows may re-use this article for personal use and teaching without any further permission.

Please cite this article as follows (you will need to access the article online to obtain the date of publication).

Asadi Gharabaghi M, Ayyoobi Yazdi N, Abrishami Z, Amini S. Splenic vein aneurysm. BMJ Case Reports 2012;10.1136/bcr.10.2011.5007, Published XXX

Become a Fellow of BMJ Case Reports today and you can:

- Submit as many cases as you like

- Enjoy fast sympathetic peer review and rapid publication of accepted articles

- Access all the published articles

- Re-use any of the published material for personal use and teaching without further permission

For information on Institutional Fellowships contact consortiasales@bmjgroup.com

Visit casereports.bmj.com for more articles like this and to become a Fellow

Keep up to date with all published cases by signing up for an alert (all we need is your email address) http://casereports.bmj.com/cgi/alerts/etoc 